\title{
El establecimiento del diario personal en el sistema literario: el diario literario en Francia y España*
}

\section{The Establishment of the Personal Diary in the Literary System: the Literary Diary in France and Spain}

\author{
Álvaro Luque Amo \\ Universidad de Granada \\ aluqueamo@ugr.es
}

ORCID iD: https://orcid.org/0000-0001-7829-5898

Michel Braud

Université de Pau et des Pays de 1'Adour

michel.braud@univ-pau.fr

ORCID iD: https://orcid.org/0000-0003-2914-5169

\section{RESUMEN}

El diario personal ha experimentado en las últimas décadas un auge tanto en el contexto editorial como en el académico. El presente artículo, fruto de la colaboración entre instituciones de Francia y España, plantea un acercamiento al desarrollo de esta forma textual en el sistema literario de tales países. Para ello, analiza la recepción de la publicación del diario personal en la crítica literaria desde el siglo XIX hasta la actualidad, así como su paso de práctica privada a texto público. El objetivo principal es definir el texto que surge de tal evolución, el diario literario, y analizar la aparición de un nuevo tipo de diarista. La perspectiva, desde un enfoque histórico y teórico-literario, se centra en el modo en que el nuevo género se ha desarrollado en estas dos tradiciones literarias.

Palabras Clave: diario personal; literatura; autobiografía; literatura francesa; literatura española.

* Este artículo se lleva a cabo en el contexto de una estancia de investigación predoctoral realizada por Álvaro Luque Amo en la Université de Pau et des Pays de 1'Adour entre los meses de septiembre y diciembre del año 2017. Esta estancia, subvencionada con una ayuda de estancias breves dentro del programa FPU (EST16/00092), estuvo supervisada por el profesor Michel Braud, que colabora como segundo autor. 


\begin{abstract}
The personal diary has experienced a boom in the editorial and academic context. This paper, fruit of collaboration between institutions of France and Spain, raises an approach to the development of this textual form in the literary system of such countries. For this, it analyzes the reception of the personal diary in the literary critic from the 19th century to the present, as well as its passage from private practice to public text. The main objective is to define the new text that emerges from such evolution, the literary diary, and analyze the appearance of a new type of diarist. The perspective focuses on the way in which this new genre has developed independently in these two literary traditions, from a historical and theoretical-literary approach.
\end{abstract}

Key words: Personal diary; Literature; Autobiography; French literature; Spanish literature.

\title{
1. ORIGEN Y DENOMINACIÓN DEL DIARIO PERSONAL EN LA LITERATURA
}

\section{1. El diario}

El término diario, empleado como sustantivo para referirse a un documento que registra lo sucedido día a día, tiene un origen muy anterior a su definitiva utilización dentro de los sintagmas diario personal, diario intimo o diario literario. Desde el siglo XIV hasta el XVIII el texto que engloba el diario es un texto de carácter cronístico que da cuenta de lo sucedido durante un periodo de tiempo en una ciudad o una navegación marítima, en relación a la contabilidad de un hogar o también a lo narrado en un cuaderno religioso. En el contexto hispánico son especialmente conocidos el Diario de navegación de Colón ${ }^{1}$, texto de carácter cronístico que relata el viaje a América acontecido a fines del XV, y el Diario espiritual de Ignacio de Loyola, del que solo se ha conservado un año de escritura entre 1544 y 1545 . Si bien este último texto puede tener un carácter más individual, cercano al moderno diario personal, esta propiedad se debe únicamente a la herencia formal de las confesiones religiosas habidas desde San Agustín. Son estos dos, en definitiva, textos cronísticos compuestos a partir de la relación histórica de los hechos externos. En el contexto francés, por otro lado, destaca el Diario de un burgués en París, texto del siglo XV de carácter anónimo y construido como una crónica histórica de París entre los años 1405 y 1449. Otros textos, además, testimonian el uso del término diario como documento; Montaigne (2016), en sus Ensayos, menciona la labor de su padre cuando «ordenaba al criado que le servía para

${ }^{1}$ El texto íntegro del diario de navegación de Colón no ha sido visto por nadie desde el siglo XVI, si bien ha llegado hasta el presente a través de las obras de su hijo Fernando Colón y de Bartolomé de las Casas. 
escribir que llevara un diario para compilar todos los acontecimientos de cierta relevancia, y las memorias día a día de la historia de su casa» $(2016,305)$. Además, el propio Montaigne escribió su célebre Diario de viaje a Italia. Finalmente, en lengua catalana son muy conocidos los textos relacionados con el libro de cuentas y la contabilidad familiar que toman el nombre de Diari o Dietari: son los casos del Dietari de Jeroni Pujades o el Diari de Joan Guardia, entre otros textos de carácter cronístico, ya sea en el ámbito de lo civil y público o de lo familiar y privado ${ }^{2}$.

Todo lo anterior demuestra cómo diario, en definitiva, es una etiqueta que se emplea durante estos siglos para definir aquel documento que, normalmente fechado, describe lo sucedido día a día a la manera de una crónica histórica. Si se consulta el Tomo III del Diccionario de Autoridades, de 1732, el término diario como sustantivo se define así:

Usado como substantivo, significa la relación histórica de lo que ha ido sucediendo por días o de día en día, en una expedición, viage, \&c. como son los que oy salen impressos en Francia, Inglaterra y Holanda con el nombre Jornales de los Sábios, que contienen lo que se ván adelantando cada día las Ciencias y Artes.

Por estas mismas fechas, de hecho, aparecen los primeros periódicos de prensa en España. Estos periódicos, como el Diario de los Literatos (1737) o el Diario de Madrid (1753), adoptan el término para referirse igualmente a la crónica noticiaria cotidiana, de tal manera que puede comprobarse el carácter público del término diario en este contexto. Sucede de igual forma en Francia, en donde la palabra journal sirvió primero para referirse a revistas de carácter científico como el Journal des sçavans (1665) y más tarde a la prensa cotidiana, como el Journal de París (1777); y también en algunas de las primeras novelas que emplean tal palabra. Daniel Defoe, en Diario del año de la peste (1722), confecciona una novela que no tiene ni el formato de un diario, ni tampoco emplea el uso de la primera persona; es una crónica histórica ficticia de lo sucedido en Londres durante 1665.

En definitiva, el término diario es utilizado durante los siglos posteriores a la aparición de la imprenta como una etiqueta que engloba textos todavía muy alejados del carácter individual de los modernos diarios personales.

\section{2. El diario personal}

¿Cuándo el término diario empieza a utilizarse para denominar el documento empleado por alguien para registrar su cotidianidad? ¿Cuándo, en resumidas cuentas, nace el diario personal? Siendo, como se sabe, textos de carácter normalmente privado que en muchos casos no llegan a salir a la luz, es muy

${ }^{2}$ Muchos de estos textos están recogidos en el artículo de Antonio Simón Tarrés (1988). 
difícil concretar las fechas exactas de su origen. Sí habría que establecer, en primer lugar, una diferenciación entre las tradiciones anglosajona y francesa, posiblemente las dos más importantes en los siglos de su surgimiento. En el contexto inglés, el diarista comienza a registrar los principales momentos de su vida en los siglos XVI-XVII. Del año 1577 al 1601, John Dee registra las visitas que recibe de celebridades y sus experimentos de química o de alquimia, pero también los acontecimientos de su familia, sus accidentes de salud y sus sueños así como el eco de las relaciones difíciles que mantiene con sus allegados. Los diarios personales fueron también muy frecuentes en el siglo XVII entre las mujeres de las nuevas clases burguesas, tal y como ha destacado Rivas Carmona (2008). Estos diarios, sin embargo, todavía no tienen la entidad del diario personal concebido en su forma actual. Samuel Pepys, con su diario fechado entre 1660 y 1669, testimonia la existencia de una práctica ya habitual en la Inglaterra de su época y, más importante, ofrece por primera vez un texto que se aproxima al diario personal moderno. Además, en el contexto inglés puede verse como algunos textos ficcionales, a diferencia de lo que sucedía con el Diario del año de la peste de Defoe, incorporan a su trama la escritura diarística; es el caso de la novela Pamela o la virtud recompensada (1740), en donde Samuel Richardson construye, derivado de la naturaleza epistolar de la trama, un diario muy parecido a lo que es el diario personal moderno. Sin ser un diario personal al uso por estar inserto en la ficción, la existencia de este tipo de textos en 1740 demuestra cómo la inglesa es una sociedad en la que esta práctica es más o menos popular a finales del XVII y comienzos del XVIII.

En el contexto francés, sin embargo, existen indicios, tal y como demuestran los estudios de Philippe Lejeune (2016) y de Michel Braud (2012), de que su popularización se produce sobre todo en la segunda mitad del siglo XVIII. Así, tanto las fechas de producción de algunos de ellos como la aparición de tal práctica en otros textos literarios arrojan luz sobre el origen y divulgación en las clases burguesas de los países europeos de los siglos XVIII y XIX. Braud (2012, 27), por ejemplo, señala un pasaje de Julie ou la Nouvelle Hélö̈se, novela de Rousseau publicada en 1761, para destacar la aparición en sus páginas del diario como una práctica cotidiana y común en la Suiza francófona de la época. Allí uno de los personajes se refiere a una señorita que escribe todas las mañanas en su journal. Si bien es cierto que el carácter de este texto todavía puede estar cercano a la confesión religiosa, la popularidad de la práctica en la sociedad es ya evidente. Braud, además, recoge $(2012,27)$ algunos testimonios como los de Lucile Duplessis o Madame de Krüdener. Esta última llega a decir lo siguiente durante el verano de 1785 :

Siento que me tranquiliza, que se alivia mi corazón al desarrollar mis pensamientos y ponerlos en papel, puesto que parece que me libero de un peso que no podría soportar sola. Es por ello que, de aquí en adelante, quiero rastrear en mi diario 
no solo cada evento interesante de mi vida, sino también cada pensamiento de mi alma [...] y la ocupación de cada día de mi existencia (Krüdener 1975, 46) 3 .

La práctica de registrar los hechos acontecidos diariamente, habitual como registro contable externo y público en los siglos anteriores, deviene por tanto práctica individual y privada en estos siglos de tránsito hacia la modernidad. No es casual en este sentido la relación entre el desarrollo de esta práctica y el advenimiento de la nueva sociedad burguesa, así como de su sistema de pensamiento ilustrado. Es, como se ha estudiado en numerosas ocasiones, la época en que el concepto de individuo libre adquiere su sentido y en que se desarrolla el espacio privado en el nuevo hogar burgués; va a ser precisamente en un contexto como el inglés, cuya revolución burguesa se produce en el siglo XVII, donde se desarrolle esta forma textual de carácter normalmente privado. Ya a lo largo del siglo XVIII esta forma se asienta también en el contexto francés y en el resto de países europeos ${ }^{4}$, si bien no se puede hablar de su consolidación definitiva hasta la publicación de estos textos a lo largo del siglo XIX.

\section{3. La publicación del diario personal}

A lo largo del siglo XIX, como se ha dicho, se producen las primeras publicaciones de diarios personales. En Inglaterra se publica así el diario de Samuel Pepys (1825), el diario de John Evelyn (1818) o el de B. R. Haydon (1853); en Francia el de Maine de Biran (1845) - un extracto publicado en una revista-, el de Maurice de Guérin (1861), el de Stendhal (1888) y el de Constant (1895); y en Suiza -y en París- se publica el que es sin duda el diario más importante de siglo XIX, el de Henri-Frédéric Amiel (1883).

Una de las clasificaciones históricas más conocidas en la historiografía sobre el género la ha llevado Alain Girard en su monográfico Le journal intime. Girard $(1963,57)$ distingue tres épocas a lo largo del siglo XIX para el desarrollo en Francia de lo que él denomina diario íntimo y que aquí se va a considerar como diario personal: una primera época de 1800 a 1860, en la que Girard incluye las redacciones de los primeros diarios; una segunda de 1860 a 1900-1910, en la que se publican estos diarios; y finalmente una tercera de 1910 hasta 1963, que es cuando escribe Girard. Esta clasificación resulta de interés porque demuestra cómo el diario personal se da a conocer como práctica popularizada durante el

${ }^{3}$ La traducción de los originales del francés, de aquí en adelante, es responsabilidad de los autores del artículo.

${ }^{4}$ En Suiza, por ejemplo, se publicó en 1773 uno de los primeros diarios personales que se conocen como es el Diario secreto de un observador de si mismo, de Johann Caspar Lavater. Por la temática demasiado apegada a lo confesional religioso, sin embargo, todavía no podría considerarse un diario moderno a la manera de los publicados en el XIX. 
siglo XIX, una vez que lo que era una práctica privada sale poco a poco al mercado a través de la publicación. Y si bien las fechas pueden variar unas décadas en el contexto anglosajón, en el francés o en el español -donde hay que esperar hasta el siglo XX-, lo cierto es que el XIX es el siglo en donde el diario personal se consolida como una realidad editorial.

Las primeras publicaciones, eso sí, se producen en muchas ocasiones en obras compiladas de textos del mismo autor; no hay exactamente una publicación exclusiva del diario. Así ocurre con Maine de Biran, cuyo diario aparece incluido en Maine de Biran, sa vie et ses pensées (1857) o con el diario de Maurice de Guerin, que aparece en el primer volumen de las Reliquiae (1861). Van a ser los diarios publicados a finales del siglo XIX los primeros que se publiquen como Journal a secas.

Lo mismo sucede, además, en relación a la publicación completa de estas obras. En raras ocasiones durante el siglo XIX se publica el diario completo de los autores. El diario completo de Samuel Pepys no se publica hasta 1895; el diario de Amiel, en su totalidad, no se termina de publicar hasta 1994. Lo que termina por demostrar que el establecimiento total del diario personal dentro del sistema editorial, y todo lo que ello conlleva, no se produce hasta bien entrado el siglo XX.

\section{4. El diario íntimo}

En 1883 se produce, como se ha visto, la publicación parcial del diario de Amiel, recogido en Fragments d'un journal intime. Se trata del diario personal más importante del siglo XIX y uno de las influencias más importantes para los diaristas posteriores. En España, por ejemplo, es notable la influencia de Amiel en autores tan importantes como Unamuno -cuyo diario íntimo es uno de los primeros encontrados en la tradición española-, Azorín o Juan Ramón Jiménez ${ }^{5}$. Henri-Frederic Amiel escribe durante toda su vida un total de 17000 páginas en el que es el ejercicio de introspección más profundo y constante de todo el siglo XIX. Como señala Alain Girard, Amiel es el primer diarista que es conocido exclusivamente por su diario - a diferencia de un Pepys, por ejemplo, cuya faceta real era la de político- y el estilo de su prosa, así como su capacidad para desarrollar su propio Yo en el texto diarístico. El diario de Amiel es muy importante, además, porque es el primero que se conoce en incorporar el adjetivo íntimo al diario. Tema este -el de lo íntimo y sus diferencias con lo privado y lo público- un tanto espinoso, lo cierto es que son los editores de Amiel los primeros en publicar un volumen titulado diario íntimo, tal y como asegura Picard $(1981,18)$, aunque el vocablo es ya ampliamente difundido. En 1857, E. Naville evoca el diario íntimo de Maine de

5 En el caso de Juan Ramón Jiménez, por poner un ejemplo, Soledad González Ródenas da cuenta de cómo leyó el diario de Amiel a partir de 1911 (2005, 107). 
Biran pero lo publica bajo el título «Pensamientos de Maine de Biran» en el volumen titulado Maine de Biran, su vida y sus pensamientos. Y diez años antes, en 1847, Amiel ya utiliza la expresión en su propio diario. A partir de ahí, el término es empleado por otros editores como Mes Inscripcions: Journal intime de Restif de la Bretonne (1889), el Journal intime de Benjamin Constant (1895), el Journal intime de Fontaney (1925), el Journal intime de George Sand (1926) o el Journal intime de Maine de Biran (1927). En 1913, Valéry Larbaud publica la primera novela titulada Diario intimo (A.O. Barnabooth, su diario intimo): hasta esta fecha, los autores titulaban diario o cuadernos los diarios ficticios.

Lo interesante de lo anterior es que a partir de Amiel cobra relevancia en el contexto francés una etiqueta como la de diario íntimo. Esta etiqueta no solo adquiere importancia como simple apelativo del diario personal en el ámbito comercial de la industria literaria, sino que tras los estudios de Alain Girard (1963) o Beatrice Didier (1976) también cobra importancia en el ámbito académico, hasta el punto de que, en muchas ocasiones, se considera la forma para denominar al diario personal dentro de la literatura. Esta etiqueta, sin embargo, no ha tenido sus equivalencias en la tradición anglosajona, donde como mucho existe el private journal. Si bien en la tradición española se ha importado directamente -y ahí está el ejemplo del Diario íntimo Unamuno (1970) o el Diario íntimo de César González-Ruano (1970)-, e incluso también en el ámbito académico se ha utilizado en las pocas incursiones a lo diarístico, en los otros contextos europeos tampoco hay una equivalencia, de tal manera que se podría decir que la problemática que este término implica es exclusiva del ámbito francés y, después de su importación, español.

La etiqueta diario intimo, así, ha suscitado controversia en su relación con la publicación de un texto que, en ocasiones, no nace para ser expuesto a la luz. Sin ser este el espacio para desarrollar esa polémica, lo cierto es que la noción de diario íntimo parece relacionarse con el texto diarístico que se publica póstumamente, sin ser concebido para su publicación, de tal manera que no podría haber diarios íntimos escritos para ser publicados. Al mismo tiempo, diario íntimo es el apelativo que se utiliza en muchas ocasiones para las relaciones entre diario personal y literatura, demostrando la paradoja que resulta el hecho de que precisamente el texto no ideado para su publicación sea el considerado literario. En las últimas décadas, sin embargo, han aparecido denominaciones como diario literario, o la misma de diario personal. Etiquetas que, además, no tienen nada que ver con el diario ficticio o autoficcional, que demarcará las fronteras entre lo autobiográfico y lo que no lo es.

\section{5. El diario literario}

Recogiendo todo lo anterior, y para establecer finalmente una diferenciación entre las denominaciones que explique el estatus del diario en el sistema literario, se puede decir que diario es una forma empleada para el texto simplemente fechado diariamente, cuyo contenido puede redundar en cualquier tipo de temática; 
diario personal es aquel texto resultante de la práctica personal e individual de llevar un diario, de tal manera que englobaría a todos esos textos que desarrollan la esfera personal del diarista; y diario íntimo es el término que, aunque en algunas ocasiones ha podido sustituir al de diario personal, se constituiría más bien como una modalidad temática del diario personal: dentro de este podría haber diarios personales de carácter público - a veces llamados en España dietarios- o diarios personales que desarrollan su privacidad -dentro de los cuales estarían los íntimos-. Pero en todo caso sería una denominación que habría que argumentar mucho más, desde un punto de vista teórico, de lo que hasta ahora se ha hecho.

Diferente sería, por otro lado, la cuestión del diario personal en la literatura. Siendo esta una cuestión que entronca directamente con la problemática autobiografía/ficción, y que ya ha sido desarrollada por Luque Amo (2016), debe destacarse que la capacidad del diario personal para ser interpretado desde la literatura no puede obedecer a las cuestiones pragmáticas de su publicación, referidas a la intención o no del autor por publicar su obra diarística. Para valorar el diario en el contexto literario es necesario tener en cuenta su capacidad para desarrollar una forma narrativa, un relato, interpretable desde coordenadas ficcionales y referenciales al mismo tiempo, que empieza en la construcción de ese Yo diarístico como personaje literario, el cual posee una psicología y una ética de vida, así como es protagonista de una acción temporal. Además, y para ello se escribe el presente artículo, es necesario que el sistema literario -con todo lo que ello implica- acepte desde un punto de vista pragmático su inclusión. Así, partiendo de la perspectiva sistémica de Schmidt $(1997,238)$ para considerar lo literario, se va a mostrar en las siguientes páginas cómo a lo largo del siglo XX, en los contextos francés y español, el diario personal se asienta como género literario.

Derivado de este establecimiento, se produce la elección del término diario literario para aquellos textos que soportan tal lectura. El diario literario no se confunde con el diario de escritor: este, en efecto, no se define por su elaboración estética, sino por su autor. El diarista proyecta la primera como una obra; en el segundo caso, sin embargo, el escritor desarrolla el aspecto cotidiano de una vida dedicada a la escritura. Los dos pueden darse al mismo tiempo, como ocurre con Gide o Renaud Camus, o no; por ejemplo, Amiel o Marie Bashkirtseff no fueron escritores, sino que produjeron un diario que se impuso en el espacio literario. Autores como Jean-Pierre Jossua (2004) o Bruce Merry (1979) ya emplean el término diario literario en sus textos. El diario literario, en definitiva, sería aquel diario personal que es susceptible de ser leído desde la literatura, tanto por razones textuales como pragmáticas ${ }^{6}$.

${ }^{6}$ La relación entre diario y literatura, como se ha dicho, afecta a toda la problemática que se ha producido en torno a las teorías sobre escritura autobiográfica y su relación con la literatura entendida como ficción. Para resolver el posible estatuto literario de la escritura autobiográfica se han propuesto diversas soluciones: se ha hablado de autoficción -tér- 


\section{LA CRÍtiCA LITERARIA Y EL DIARIO PERSONAL: FRANCIA Y ESPAÑA}

\section{1. El diario y la crítica literaria francesa}

El diario personal en el sistema literario, como sucede con las obras autobiográficas en general, ha sido objeto de todo tipo de críticas negativas referidas a su naturaleza como obra acabada, pero también a la práctica misma de llevar un diario, o incluso a lo que ello supone para la figura del escritor. Las primeras observaciones, en este sentido, aparecen cuando A. Jullien publica su Essai sur l'emploi du temps (1808), una especie de manual pedagógico dirigido a los jóvenes de su tiempo en el que, entre otras cosas, recomienda el empleo del diario personal como ejercicio cotidiano. Como señala Alain Girard (1963, 570), las críticas a este tipo de ejercicio son casi todas de tipo psicologista, referidas a la figura del diarista como personaje egoísta y onanista. Es un contexto en el que no se ha editado todavía ningún diario.

A partir de la década de 1880, sin embargo, y tras las primeras publicaciones regulares de diarios mencionados como el de Amiel (1883) o el de los hermanos Goncourt (1887), aparecen algunas críticas dentro del sistema literario. El diario de Amiel es precisamente el primero que llama la atención: Paul Bourget sostiene que se trata de un «interminable monólogo de un Narciso

mino confuso y abarcador cuyas diferencias con lo autobiográfico no han sido bien aclaradas hasta la última publicación de Manuel Alberca (2017)-, de literatura de no ficción -etiqueta anglosajona que surge en el contexto de la escritura literara periodística y que es una mera etiqueta comercial, no teórica- o incluso de antificción -propuesta por el mismo Alberca en la obra citada, basándose en la misma acuñación de Lejeune, si bien el propio autor es consciente de su debilidad teórica-. Ninguna de estas etiquetas, no obstante, soluciona la relación que muchos autores aceptan entre literatura y ficción pura, que excluiría a todo texto de carácter autobiográfico y por lo tanto histórico. A medio camino entre esos dos estatutos -ficcional y autobiográfico-, autores como Pozuelo Yvancos y Darío Villanueva han esbozado ya una suerte de poética autobiográfica que busca explicar esa lectura ficcional del texto autobiográfico. En relación al diario, esto se muestra en el artículo citado de Luque Amo (2016), en donde se intenta extrapolar este doble estatuto a la escritura diarística. La definición de la que allí se parte pertenece a Enric Bou, quien ha definido al diario en la literatura así: «El diario es una crónica cotidiana, escrita desde el presente, de una experiencia personal. Como escribió Alain Girard, constituye un "Nouveau genre littéraire et fait de civilisation" que se ha impuesto en los dos últimos siglos. [...] Necesita el diario de unas mínimas condiciones: anotaciones periódicas, atención hacia lo inmediato, entidad literaria» (Bou 1996, 124). Lo que busca el citado artículo es explicar precisamente lo que Bou no desarrolla, que es esa «entidad literaria» del diario y la posible lectura performativa de este. El presente artículo es una continuación historicista y pragmática del anterior, en la medida en que busca explicar cómo se desarrolla esta forma narrativa en el sistema literario moderno. Sin espacio para ampliar la cuestión teórico-literaria, por tanto, se parte del anterior punto para ofrecer otra perspectiva que, a fin de cuentas, no busca otra cosa que dar explicación a esa «entidad literaria» del diario; esta vez desde un punto de vista sistémico. 
psicológico» $(1920,271)$ y Ernest Renan, en una crítica al Journal intime, habla del diario personal como «un género peligroso, a veces insano [...]. El hombre que tiene el tiempo de escribir un diario nos parece que no ha podido comprender la vastedad del mundo» ${ }^{7}$. Más incendiario aún es el juicio que expone Ferdinand de Brunetière, quizás uno de los críticos literarios más conocidos de finales del siglo XIX, en su artículo «La litterature personnelle», escrito a partir de las publicaciones, como señala Lejeune (1990, 134), de los diarios de los Goncourt y Marie Bashkirtseff. Brunetière llega a decir que «todos los Diarios y Confesiones de este género tienen algo todavía más insostenible que su fatuidad, su total insignificancia» $(1888,440)$. Y trata un punto todavía más interesante, su incapacidad para ser un texto literario: «la literatura es impersonal, y aquello que es personal no puede jamás devenir literario» $(1888,442)$.

Todas estas críticas, que prolongan los prejuicios de carácter psicologista de las primeras aproximaciones del siglo, redundan además en una idea principal: durante las últimas décadas del XIX y principios del XX, el diario personal publicado no se considera en ningún caso un género literario. Si bien hay excepciones en autores del calibre de un Anatole France, que alaba las virtudes de lo autobiográfico, por lo general el diario tiene una recepción bastante escéptica entre los primeros críticos, y es algo que realmente se prolonga hasta bien pasada la mitad del siglo XX. En 1947 Duhamel habla de «las deformaciones y perversiones» $(1947,25)$ que esta práctica del diario personal favorece, y el poeta Paul Valéry declara en 1944 que él jamás ha escrito un diario ${ }^{8}$.

En último lugar, alguien como Marcel Proust declara en un pasaje de En busca del tiempo perdido la falta de «valor alguno» de la «literatura de anotaciones», la cual es un arte de lo «supuestamente vivido» y está lejos de la «grandeza del arte verdadero» $(2009,224-225)$. Se puede ver cómo, además de los reproches de carácter ético, desde los comienzos se duda de la supuesta capacidad de lo autobiográfico para ser leído desde lo literario. Una idea que resultará de mucho interés más adelante.

\section{2. El Journal de Gide}

Décadas después de la primera hornada de publicaciones de diarios a finales del XIX, se publica en Francia el que es posiblemente el diario personal más importante del siglo XX en este ámbito: el Journal de André Gide, publi-

\footnotetext{
${ }^{7}$ En «Henri-Frederic Amiel», Journal de debats, 30 septembre 1884.

8 Yo no escribo, no he escrito nunca un diario de mis días. ¿Qué me importa mi biografía? ¿Qué me importan mis dias transcurridos? [...] A mí no me gusta para nada volver por las antiguas sendas de mi vida. ¡No seré yo quien busque el tiempo perdido! (Berne-Joffroy 1944, 3-4).
} 
cado en 1939. A lo largo de toda su obra ficcional, Gide experimentó en numerosas ocasiones con la forma diarística en la novela -su primer novela, Les Cahiers d'André Walter (1891), es un diario ficticio- y desde 1887 había llevado un diario con cierta regularidad, que publica en varias ediciones a partir de 1931 hasta su edición definitiva en 1939. Lo interesante de lo anterior estriba en el proceso que lleva a Gide a tener en cuenta su obra; como señala Martine Sagaert (2012), durante las primeras décadas del siglo, antes incluso de considerar la publicación integral de su diario, Gide declina las posibilidades formales y editoriales: ya se trate de una tirada limitada o parcial de su obra, incluso de un diario sin fechas. En cambio, después de 1925, y de la publicación de Les Faux-Monnayeurs, que supone una de sus obras cumbres en otro diario ficticio, Gide prepara sistemáticamente su Journal para la publicación, desarrollando una verdadera estrategia editorial: publicaciones en revistas y en diferentes volúmenes y todo tipo de divulgación literaria.

En este sentido, se hace evidente que Gide no quiere que su diario figure como uno de sus textos menores en su obra y en 1939 publica su Journal desde 1889 a 1939 en la edición de la Pléiade, en Gallimard, en la que es posiblemente la colección literaria con más prestigio de la Francia de aquel entonces. Lo realmente interesante de esta edición, además de constituir la confirmación del Journal de Gide como obra, es que se trata del primer diario en figurar en una colección con tal fama, junto a otros clásicos europeos desde Plutarco hasta Balzac y Baudelaire. La decisión de publicar ahí es, además, del propio Gide, que como es sabido es uno de los fundadores de la revista NRF, germen de la posterior editorial Gallimard. Gide, con esta decisión, no solo está reclamando y reafirmando el valor de su obra diarística a diferencia de los diaristas del XIX, sino que está habilitando la entrada del diario personal como género dentro del sistema literario. Si un diario puede figurar al lado de obras como la de Balzac o Montaigne se debe a que aspira a tener un valor literario, y esto va a ser fundamental para el establecimiento del género diarístico en Francia.

Los nombres de los críticos que poco tiempo después valoran el trabajo de Gide pueden arrojar una idea de la importancia que adquiere el Journal tras ser publicado. Para Jean-Paul Sartre, como ha señalado Francis Walsh $(2014,77)$, resulta una influencia principal en la redacción de sus Carnets de la drôle de guerre, y un joven Roland Barthes le dedica uno de sus primeros estudios en 1942: «Notes sur André Gide et son Journal». Estos acercamientos no tratan directamente la consideración literaria del diario de Gide, pero su mera existencia arroja luz sobre la entrada del Journal de Gide dentro del sistema literario.

A pesar de lo anterior, no hay todavía en estas décadas unanimidad sobre el diario personal como forma literaria. En 1955, Maurice Blanchot, en su conocido texto «El diario íntimo y el relato», despoja al diario personal de 
todos los caracteres que lo acercarían al ámbito literario y, lo que es casi peor, incurre en algunas de las críticas decimonónicas que se le hacía a esta forma de escritura. Blanchot señala:

Hay, en el diario, como la feliz compensación, una por otra, de una doble nulidad. El que no hace nada con su vida escribe que no hace nada, y he aquí, sin embargo, algo realizado. El que se deja apartar de la escritura por las futilidades del día, vuelve a esas inutilidades para contarlas, denunciarlas o complacerse en ellas, y he aquí un día repleto. «Esta es la meditación del cero sobre sí mismo», de la que habla valientemente Amiel $(1959,209)$.

Blanchot, por lo tanto, se centra en la «insignificancia» de una escritura que está lejos de ser literatura y más cerca de ser una «trampa».

\section{3. El diario y la crítica literaria francesa: de 1950 en adelante}

De los años cincuenta en adelante, no obstante, la opinión general sobre el diario personal en su relación con el sistema literario empieza a cambiar. Si en 1948 Gusdorf publica La Découverte de soi -cuyo primer capítulo está dedicado al diario- y en 1956 su célebre Condiciones y límites de la autobiografía, en 1952 Michèle Leleu da a la imprenta el primer monográfico sobre el diario, y una década después, en 1963, Alain Girard publica el que va a ser posiblemente el primer gran libro sobre el diario en Francia: Le journal intime. Aquí Girard ya va a partir de una idea muy clara que anticipa desde el título de la introducción: el diario que él denomina íntimo es «un nuevo género literario» (1963, VII). Si bien es una cuestión que no será tratada a lo largo del voluminoso tomo más allá de un breve pasaje de las conclusiones titulado «L'art du journal», como señala Lejeune para reprochárselo $(1997,66)$, lo cierto es que la asunción del diario como género literario implica un cambio en la perspectiva de la crítica francesa.

En los años setenta se confirma el nuevo interés por el diario personal desde la crítica. Los acercamientos hasta este momento, tal y como señala Lejeune, habían tenido un carácter más psicologista por un lado -en el caso de Leleu- y más sociológico por otro - como Girard-, y no es hasta la publicación en 1976 del Le journal intime de Béatrice Didier cuando aparece el primer monográfico que analiza el diario como texto literario. Allí Didier deja clara su postura: «Por más proteiforme que sea, el diario es un género literario en el que operan varios mecanismos de escritura. Cabe señalar entonces que la constitución del diario en género literario solo se produjo progresivamente» (1976, 139).

Justo en esta época, además, se celebra en Grenoble el coloquio «Le journal intime et ses formes litteraires», que, aunque no supone un avance en la problemática del diario en el sistema literario, testimonia ya cierta asunción por 
parte de la crítica de los rasgos literarios de esa forma de escritura y de la confirmación del género en una zona aledaña al canon ${ }^{9}$. Hay que recordar, en este sentido, que estos son también los años en los que se publica el famoso libro de Lejeune (1975), Le pacte autobiographique, en donde el crítico ya trataba lo autobiográfico como un género literario -sin abundar en el tema- en el que incluía como subgénero el diario.

Desde las décadas de los años 80,90 y hasta la actualidad, el diario personal en Francia es objeto de un reconocimiento limitado pero efectivo en el sistema literario. En el ámbito académico los artículos crecen exponencialmente y las grandes monografías recientes -Simonet Tenant (2004), Michel Braud (2006) - confirman el establecimiento del diario personal en un ámbito, el universitario y académico, que normalmente tarda en sancionar lo establecido previamente por las instituciones editoriales y comerciales. En este sentido, y si Gide fue la publicación más importante de la primera mitad del XX, a lo largo de la segunda mitad se van a normalizar las reediciones de diarios clásicos como el de los Goncourt (1956), el de Maine de Biran (1957), el de Benjamin Constant (1952) o el de Amiel (1959); durante estos años se produce además la publicación íntegra de muchos de estos diarios, como ocurre con la monumental obra diarística de la edición completa de los diarios de Amiel, que lleva a cabo Monnier entre 1976 y 1994. Muchos de estos diarios se publican en editoriales literarias, como Gallimard en el caso del Journal intime de l'année 1866 (1959) de Amiel, el Journal (1959-1976) de Jules Michelet o el mismo del propio Constant (1952). Además, van apareciendo los diarios de autores clásicos del género: ocurre con Julien Green, cuyo diario se publica desde 1938 a 2006, o con Paul Léautaud (1954-1966), entre muchos otros. Además, aparecen autores como Renaud Camus, cuya consideración del diario es plenamente moderna, y sus diarios están escritos desde el primer momento con una clara conciencia literaria tanto artística como comercial.

Todas estas publicaciones, en definitiva, corroboran la aceptación académica del diario dentro del sistema literario. Esto no quiere decir, con todo, que las voces discordantes desaparezcan del panorama: alguien como Pierre Bourdieu va a declarar en 2004, ante su propia obra autobiográfica, que no tiene intención de someterse al género de la autobiografía, «cuyo carácter a la vez convencional y engañoso ya he destacado en reiteradas ocasiones» $(2006,13)$. En este sentido, la inclusión del diario personal dentro de los géneros autobiográficos y la problemática que de esto se deriva va a suponer el cuestionamiento más fuerte del diario como género literario en la actualidad, si bien esto obedece más bien al debate clásico de los estudios teórico-autobiográficos que, como se ha señalado, merece espacio aparte.

9 V. Del Litto se propone en este volumen «analizar los problemas múltiples puestos por este nuevo género que es el diario íntimo», si bien añade: «si género hay» (1978, VII). 


\section{4. Roland Barthes y el nuevo diario en Francia}

Por recurrir a una figura que englobe todo lo anterior, la posición teórica de Roland Barthes puede resumir aquello que Philippe Lejeune ha definido como «el proceso» (1997); esto es, la persecución teórico-crítica de los géneros autobiográficos al fin del siglo XIX y a lo largo del XX. Barthes le dedica tres textos principales a la cuestión del diario: las mencionadas «Notes sur le Journal de Gide» (1942), la reseña del Journal intime de Alain Girard de 1966 y finalmente su Délibération (1979). Si bien en el primero de estos textos hay pocas reflexiones sobre el diario, en los dos últimos hay una crítica contundente contra el género diarístico que introduce matices enriquecedores para el debate sobre su posición dentro del sistema literario.

La opinión de Barthes sobre el género diarístico se intuye ya en su temprano texto sobre el diario de Gide; allí va a señalar que no se cree capaz de encontrar valioso un diario cuyo autor carezca de interés (2002a, 33), como si texto y autor estuvieran inevitablemente ligados. Si bien es cierto que lo autobiográfico es el campo por excelencia para esta identificación entre obra y autor, los juicios de Barthes esconden cierta tendencia a considerar la imposibilidad del diario como obra literaria independiente (2002a, 42). Esto se va a confirmar en su reseña al libro de Girard; aquí ubica al diario en esa delgada línea que separa la escritura de la obra $(2002 b, 806)$. Pese a esto, reconoce que el diario se ha constituido como género literario, aunque en todo momento lo concibe como «un desafío a la literatura» $(2002 b, 806)$. Los motivos para sostener esto están claros: Barthes interpreta el texto diarístico en las coordenadas que lo hacía Girard, inseparable de la práctica misma de llevar un diario y, por tanto, atado a las polémicas cuestiones en torno a su carácter privado, su constitución como obra y su definitiva publicación. Barthes, aunque parta de esa relación entre diario y literatura, no olvida en todo momento el deseo de esta escritura por «escapar, de cierto modo, de la literatura» (2002b, 810). En su último texto, publicado trece años después, experimenta con sus propios escritos diarísticos para llegar a la conclusión de que no puede publicar su diario. Allí dice: «el diario no responde a ninguna misión. [...] El diario no puede alcanzar a ser libro u obra; solo es un álbum, para recurrir a la distinción mallarmeana (es la vida de Gide la que es una obra, no su diario)» (2002c, 678679). Esta idea tan cercana a las anteriores lo conduce más tarde a su conclusión definitiva, según la cual el estatuto literario del diario «se le escapa de los dedos» $(2002 \mathrm{c}, 680)$ en la medida en que este no puede satisfacer las funciones básicas de lo que él denomina Texto: a saber, la construcción de un ritmo -imposible en tanto que escritura intercalada, como señala Genette- y lo que denomina un señuelo, porque el Yo no puede nunca alcanzar su imagen (2002c, 681). Barthes prolonga la reflexión desarrollada por Blanchot en L'Entretien infini, para quien el diario es un tiempo sin acontecimiento, sin límite, sin coherencia ni regularidad $(1969,564)$. 
En resumidas cuentas, Barthes, a través de un contradictorio discurso, duda constantemente de las posibilidades literarias del diario, al mismo tiempo que no puede evitar situarlo en el contexto literario, recalcando su naturaleza paradójica. Más interesante resulta todavía, en este sentido, que el propio Barthes cultivara esta forma en diversas ocasiones y que póstumamente saliera a la luz su famoso Diario de duelo. Gerard Genette, en la famosa respuesta a la Délibération barthesiana que supuso su texto «Le journal, l'antijournal», incide precisamente en esta cuestión, al preguntarse por la fascinación de Barthes por el diario teniendo en cuenta su animadversión $(1999,343)$. Más adecuada es todavía esta pregunta si se tiene en cuenta la siguiente entrada del Diario de duelo de Barthes, en la que sostiene: «No quiero hablar de esto [la muerte de su madre] por temor a hacer literatura $-\mathrm{o}$ sin estar seguro de que eso no lo sería- aunque de hecho la literatura se origine en estas verdades» $(2009,27)$. Barthes, así, está aceptando -con todas sus dudas- la posibilidad de encontrar literatura en el diario personal. De esta premisa parte precisamente Genette en su texto al afirmar que «el valor literario (estético) es una más de las virtudes posibles del diario» $(1999,340)$, compartiendo un pensamiento que realmente, como se ha señalado antes, va a ser predominante en la crítica académica y literaria desde la décadas de los 80 en adelante.

Fruto del definitivo establecimiento del diario en el sistema literario, como se anticipaba antes, es la aparición del diarista profesional, que podría definirse como aquel que ya concibe su obra diarística dentro del sistema literario, con todo lo que ello implica. En Francia, durante la segunda mitad del siglo $\mathrm{XX}$, el diario está bien establecido en el sistema literario francés, pero atendiendo en cada caso a diferentes circunstancias editoriales. En un primer momento, el diario sigue siendo una práctica de escritura personal, cuyo interés como cuaderno privado es anterior a la posibilidad de ser publicado, si bien la publicación acaba produciéndose. Algunos diarios todavía se conocen póstumamente (Michel Leiris), pero la mayoría son publicados por su autor, ya sea de forma regular y ordenada, en conjuntos de algunos años (Henri Bauchau, Gabriel Matzneff, Pierre Bergounioux) o bajo la forma de uno o más fragmentos (Christian Bobin, Roland Jaccard, Annie Ernaux). Si estos textos son generalmente los de escritores reconocidos, el diario puede también ser ahora la primera obra literaria de un autor. Charles Juliet, quien hasta entonces solo había dado a la imprenta algunos folletos de poesía, publica dos volúmenes de su diario en 1978 y 1979, de tonalidad muy íntima. Por supuesto, ya se conocen algunos diarios que con anterioridad le habían dado la fama a su autor, pero era de modo póstumo (Amiel) o por lo menos al fin de su vida (Léautaud); Juliet es el primero en obtener el reconocimiento de escritor por su diario antes de publicar relatos autobiográficos, cuentos y ensayos. Otro escritor, cuya notoriedad permanecía bastante limitada antes, impone una nueva forma editorial en la misma década: Claude Mauriac publica de 1974 a 1988 diez volúmenes 
de su diario bajo el título El tiempo inmóvil. Mauriac, sin embargo, no presenta entradas diarias ordenadas cronológicamente: por el contrario, yuxtapone fragmentos de diferentes épocas, que conservan las fechas pero se ordenan casi de forma aleatoria. En este caso, como en el anterior, la motivación inicial del diario no se relaciona con la publicación, sino que el diario se literaturiza a partir de esta.

Estos textos anticipan, en suma, esa figura del diarista que ya escribe inserto en el sistema literario y que se desarrollará en el último punto.

\section{5. El diario personal en España}

En España, a diferencia de Francia o Inglaterra, la aparición del diario personal es muy tardía, y no se puede hablar de diarios susceptibles de ser interpretados desde lo literario hasta el siglo XX. Así, si bien autores como Jovellanos o Leandro Fernández de Moratín ya escriben textos que se titulan como diarios - no publicados hasta el siglo XX- y que son textos diarísticos personales, para encontrar la concepción moderna del diarismo hay que esperar a los autores del 98, que ya han leído algunos de los grandes diarios franceses. En este sentido, se ha hablado en muchas ocasiones del tópico que contrapone lo español a lo autobiográfico, toda vez que el carácter patrio se opondría a lo confesional por una serie de razones socioculturales. Autores como Anna Caballé ya han desmentido este tópico en varias ocasiones y, en este caso, habría que apuntar más bien a la tardía incorporación del ámbito español al contexto literario moderno europeo. De hecho, van a ser autores de clara influencia francesa e inglesa los primeros que cultivan diarios literarios entendidos al uso.

En el caso de los autores del 98, destaca la figura de Azorín, quien no escribe un diario autobiográfico, pero introduce la forma diarística en escritos novelísticos como Diario de un enfermo (1901) o Charivari, crítica discordante (1897); en la misma línea, Unamuno experimenta con el diario en Cómo se hace una novela (1927) y además lleva su Diario íntimo que no se publica, no obstante, hasta 1970; y finalmente Pío Baroja publica en 1918 Las horas solitarias, un texto que tiene mucho de diario literario moderno. En el campo de la poesía, además, Juan Ramón Jiménez publica Diario de un poeta recién casado en 1916 y Dámaso Alonso va a utilizar el subtítulo de «Diario íntimo» para su famoso poemario Hijos de la ira de 1944. Estos textos no tienen, sin embargo, una verdadera correspondencia -en algunos casos por la falta de identificación autobiográfica; en otros por la naturaleza documental o lírica del texto- con los grandes diarios franceses, y solo la publicación de Iluminaciones en la sombra (1910), el diario de Alejandro Sawa, constituye la primera aparición de un diario literario en el contexto español. Sawa, conocido en la bohemia madrileña por su experiencia parisina, desarrolla la influencia francesa en un texto que se publica de forma póstuma -a pesar de los repetidos intentos 
de Sawa por publicarlo-, gracias a las gestiones del propio Valle-Inclán, en 1910. El texto, una suerte de diario lírico, posee una naturaleza literaria evidente y un formato diarístico, como el propio autor explica en la primera entrada de la obra:

Me he puesto a escribir estas hojas de mi dietario. Lo mismo me propongo hacer todos los días; luego repartiré mis jornadas en zonas de acción paralelas, aunque heterogéneas; y digo que paralelas, porque todas han de estar influidas por el mismo pensamiento que me llena por completo: la formación de mi personalidad (Sawa 2009, 37-38).

Pese a este primer acercamiento, la publicación de casi todos los diarios personales que pueden ser interpretados desde lo literario no se produce hasta la segunda mitad del XX. Es el caso del diario de Emilio Prados (1968), el de César González-Ruano (1970), el de Rosa Chacel (1982), el de Max Aub $(1975)^{10}$ o el de Manuel Azaña $(1967)^{11}$. De los anteriores, posiblemente el diario de mayor trascendencia sea el diario de Rosa Chacel, como Anna Caballé apunta al señalar que «es el exponente más valioso del diarismo español contemporáneo por la fuerza, capacidad de desarrollo y autenticidad de su escritura» (Caballé 2015, 140).

En el contexto catalán surge en esta época la figura de un Josep Pla, que va a dar a luz el texto diarístico con más fama en el siglo XX español: El Quadern gris. Publicado como el primer tomo de sus obras completas, este texto es el resultado del desarrollo literario que Pla lleva a cabo a partir de unos diarios personales fechados muchos años atrás. Más allá de la problemática que esto conlleva para el pacto autobiográfico, el texto tiene un carácter novelístico muy evidente, e incluso alguien como Xavier Pla lo cataloga de diario ficticio (1996, 1232). Otros textos diarísticos de Pla, como sus Notes disperses (1981), resultan también muy interesantes, pero la potencial capacidad de $E l$ Quadern Gris -traducido tempranamente por Dionisio Ridruejo en 1975- para ser el gran diario literario español se pierde en lo que tiene de novela autoficcional. En este sentido, Pla está muy lejos de un Amiel o un Gide.

Para hallar la culminación del diario literario habrá que esperar a los autores que pueden encuadrarse dentro de la categoría de diarista profesional que antes se ha aventurado. Tales autores publican sus diarios desde finales de los 80 en adelante y logran trascendencia literaria precisamente por ello. Son los casos de Andrés Trapiello, Miguel Sánchez-Ostiz e Iñaki Uriarte entre otros.

${ }^{10}$ La primera edición de La Gallina Ciega, diario de Max Aub, se lleva a cabo realmente en México. No se puede encontrar una edición española hasta 1995.

${ }^{11}$ Los diarios de Azaña se han publicado en varias ediciones desde 1967, que se publican parcialmente en sus obras completas editadas en México por Juan Marichal. No es hasta 1997 cuando va a aparecer la primera edición completa de sus diarios. 


\section{6. El diario y la crítica literaria española}

Desde el punto de vista de la crítica, el diario adolece en España de los mismos problemas que en Francia, con el añadido de que es una cultura en donde el diario aparece un siglo después. Esto va a alimentar el mencionado tópico de la incompatibilidad entre lo autobiográfico y lo español. Eusebio García-Luengo va a señalar, en las páginas de un ABC de 1955, lo siguiente:

El diario supone, primeramente, una dedicación estricta y específicamente literaria, que el escritor español no suele mantener, porque en cierto modo implica una servidumbre que le amputa de otras actividades vitales a las que considera más importantes [...]. Es raro suponer en un escritor español la disciplina, la minuciosidad y, en cierto modo, la cicatería que se precisan para llevar un diario (García-Luengo, 2015).

El tópico de la incompatibilidad es adornado aquí además con el prejuicio del diarista como sujeto egoísta y ensimismado. Añade García-Luengo: «el español siente repugnancia por ciertas actitudes literarias a las que considera narcisistas y delicuescentes». Como se ve, el autor comparte la misma perspectiva de los detractores franceses del diario.

En el primer acercamiento al diario como texto, la antología de Manuel Granell y Antonio Dorta publicada en 1963, este último explica que «tampoco parece propicia la lengua española para la germinación del Diario íntimo» debido a que había dado hasta ese momento «pocos cultivadores» (1963, XL). Dorta, que cae ligeramente en el tópico de la incompatibilidad, al menos parte del hecho contrastable de que, hasta ese momento, los diarios editados en España son escasos y marginales.

La escasa crítica que le va a prestar atención durante esas décadas previas a los años 80 y 90 va a tener unos prejuicios muy parecidos a los encontrados en la crítica francesa de fines del XIX y principios del XX. Guillermo de Torre va a sostener en 1970: «Por mi parte me sumo a quien ve en todo diario íntimo un cementerio de artículos abortados. Los que emergen de tales ruinas son aquellos que rebasan la unilateralidad de un yo y se extienden a muchos sectores intelectuales») $(1970,606)$. Guillermo de Torre está hablando, ciertamente, de la capacidad de estos diarios para ser atractivos desde un punto de vista literario, lo que parece negar. Habrá que esperar, como se ha dicho, a la publicación de muchos de los diarios de los años setenta y ochenta, y a la aparición de los primeros diaristas que conciben su obra con vistas a la publicación para encontrar un verdadero establecimiento del diario en el contexto literario. En 1990, precisamente en una reseña a los diarios de Andrés Trapiello, Ángel Basanta va a declarar la buena salud del género autobiográfico, señalando que «memorias, diarios, autobiografías y otros escritos semejantes [...] han recuperado su lugar editorial en los últimos lustros» (Basanta 1990). En este sentido, aparecen editoriales como Pre-Textos o Renacimiento que dedican cada 
vez más espacio a los diarios en colecciones literarias -años más tarde otras se sumarán a esta labor, como Acantilado o Alba-, y el nombre de ciertos diaristas, como Andrés Trapiello, Miguel Sánchez-Ostiz, Laura Freixas o Iñaki Uriarte entre otros, empieza a adquirir fama en el contexto literario. En lo que respecta a la crítica comercial, los diarios van a tener espacio con relativa frecuencia en los suplementos culturales del ámbito español e incluso protagonizan monográficos en revistas, como es el caso del número 167 de la revista Letras Libres (Gascón et alii 2015). Juan Bonilla (2016) certifica este auge en su artículo «Auge de un género: los diarios, literatura del yo».

Desde el punto de vista académico, en las décadas noventa y posteriores se muestra a su vez cómo el diario ha entrado en el canon. En 1996 la Revista de Occidente va a dedicar un número al diario íntimo, con traducciones de los trabajos de Beatrice Didier y Alain Girard entre otros, en el que va a ser el mayor acercamiento al diario personal en la literatura desde la antología de Granell y Dorta. En 1998, Andrés Trapiello le dedica el ensayo más voluminoso hasta la fecha a la escritura de diarios (Trapiello 1998), y ya entrado el siglo XXI se van a multiplicar los acercamientos teóricos y analíticos al diario: Danielle Corrado va a publicar Le journal intime en Espagne en el año 2000; el grupo de investigación de la UNED dirigido por José Romera Castillo, con el nombre de SELITEN@T, va a engendrar artículos dedicados al diario con frecuencia; y la Unidad de Estudios Biográficos, de la Universidad de Barcelona y dirigida por Anna Caballé, va a tener en el diario personal una de sus líneas principales de investigación. En el plano ensayístico, en 2015 Anna Caballé va a publicar Pasé la mañana escribiendo. Poéticas del diarismo español, una suerte de diccionario del diario personal en España, y en 2017 Manuel Alberca presta atención a muchos diarios que incluye dentro de la literatura autobiográfica española en el citado La máscara o la vida. Muestra de este impacto en el canon, finalmente, son los apartados que Jordi Gracia dedica al diario en la Historia y crítica de la literatura española, de Francisco Rico, en primer lugar (Gracia y Mainer 2000), y en la Historia de la literatura española, de José-Carlos Mainer, después (Gracia y Rodenas de Moya 2010).

\section{El diario literario en Francia y ESPaÑa}

\section{1. El nuevo diarista y la literatura}

Lo más interesante de esta incorporación del diario al canon literario en los contextos francés y español es la aparición de un tipo de texto que por primera vez está inserto en el sistema literario desde su génesis. Cuando el nuevo diarista es consciente de las posibilidades literarias de su texto, este cambia inevitablemente. Este cambio, eso sí, no tiene por qué afrontarse solamente desde el punto de vista de lo íntimo y lo privado, como se ha hecho en nume- 
rosas ocasiones, sino que también implica modificaciones desde un punto de vista retórico, artístico, literario.

La cuestión de la intimidad, que ya se ha abordado en otro lugar (Luque Amo, 2018), no debería tratarse tanto desde la perspectiva del contenido narrado, sino del modo en que este contenido es narrado. La intimidad, así vista, es una construcción literaria, una intimidad hecha literatura en términos de César Aira $(2008,7)$, y lo que resulta de verdad interesante es cómo se ha construido históricamente esta intimidad en el texto -cuando el texto no se va a publicar (Pepys); cuando el texto quizás se puede publicar en una forma todavía desconocida (Amiel); y cuando el texto se revela como una forma para publicación en el mismo proceso de escritura (Gide)-. En un artículo de 2015, Luis Antonio de Villena (2015) denuncia la falta de una «intimidad psíquica y verdaderamente íntima, sexual, afectiva o de análisis» en el diarismo contemporáneo español. Laura Freixas, de esta misma forma, señala que «la literatura española ha llegado al diario íntimo en un momento en el que el concepto de intimidad» ha sido «desnaturalizado» (1996, 14), y Anna Caballé habla de la «apropiación literaria» del diario y ofrece la opinión de José Luna Borge, quien critica la intención del diarista por publicar su texto, lo que provoca que el diario ya no sea «ningún misterio» y que no haya «vida íntima», sino «espectáculo» (Caballé 2015, 41). Nuestra tesis, sin embargo, es que esta «apropiación literaria» del diario ya se lleva a cabo en el autor que inaugura esta, como es Amiel, que llega a su culmen en un Gide, y que a partir de las décadas de los ochenta y los noventa da como fruto un nuevo tipo de texto y de autor: el diario y el diarista literarios. De esta forma, no se trataría tanto de que un Amiel o un Constant desarrollasen más o menos esa faceta privada - puesto que estos autores están hablando desde una perspectiva, casi cuantitativa, que mide la cantidad de privacidad expuesta- sino que la construcción de su texto diarístico como obra es diferente a la de los diaristas posteriores, de Gide en adelante.

El elemento a desarrollar sería el modo en que la práctica del diario personal evoluciona hasta dar lugar al género literario actual y, lo que resulta más revelador, cómo esta evolución puede encontrarse dentro de los mismos diaristas. Un diarista como Amiel no escribe en un comienzo para publicar; sin embargo, al final de su obra se muestra muy consciente de la posibilidad de publicación. Lo mismo sucede con Gide, quien muestra intención de publicar su obra diarística mucho antes, como se ha visto. Incluso en el contexto diarístico actual, muchos autores de los que ahora se hablará no comienzan sus diarios con una clara intención de publicación.

Todo lo anterior no quiere decir que el diario pueda tener o carecer de un carácter literario según la intención o no de publicación de sus páginas, pero sí es cierto que hay un cambio en la forma de afrontar el diario y que ese cambio se vislumbra en Amiel, se confirma en Gide y se desarrolla en el dia- 
rismo contemporáneo. En estas páginas no hay espacio para un estudio analítico teórico-literario de estos nuevos textos, pero sí se va a efectuar una introducción a la nueva perspectiva teórica que aporta el llamado diarista profesional en el contexto de la relación entre diario y literatura ${ }^{12}$.

\section{2. El diario literario en Francia}

Tal y como se ha dicho, el Journal de Gide afirmó ya en 1939 la posibilidad de entender el diario como género literario y manifestó su fuerza de representación. A partir de los años 60, algunos autores, escasos todavía, explotan en el contexto francés esta fuerza estética y escriben diarios con el proyecto de publicarlos.

Marcel Jouhandeau, aunque había publicado antes numerosos relatos y ensayos de inspiración autobiográfica que sembraron la discordia por la denuncia de las bajezas de la vida de provincia o por la mezcla de desenfreno y de misticismo, tiene ya más de sesenta y ocho años cuando comienza en 1957 la redacción de sus Journaliers. En estos, narra en el curso de los días -pero a un ritmo que no está encarcelado por el calendario- el infierno de su matrimonio y sus deseos homosexuales sobre un fondo de lecturas religiosas. Con estos componentes, el autor construye un relato insolente, sostenido en el choque violento de los deseos y los estados de ánimo, que se reproduce en 28 volúmenes de Journaliers del 1957 al 1974 (publicados de 1961 a 1982).

En 1950, Jacques Audiberti publica un texto desconcertante, Cent jours, subtitulado 'novela', que combina anotaciones fechadas de su cotidianidad y fragmentos de ficción, sin relación directa entre ambos. En 1965, cuando se sabe enfermo, escribe un diario sin fechas pero con anotaciones cronológicamente ordenadas, con vistas a una publicación: Dimanche m'attend. Reflexiona a partir de un marco diarístico para divagar sobre los aspectos más diversos: la editorial Gallimard, la religión, los recuerdos de infancia... y añade una reflexión continua sobre la muerte: «¿Qué esperas, Jacques, mi bello, que es-

${ }^{12}$ La tesis es clara: la proliferación de textos diarísticos de carácter autobiográfico y su aceptación en el canon -crítico, académico y comercial- permiten la consideración del diario personal, desde un punto de vista pragmático, como un género literario. Con más detenimiento, se podría hablar históricamente de la evolución del diario personal como un género derivado de textos morales y didáctico-ensayísticos en mezcolanza con los géneros autobiográficos puros y la novela, pero en los capítulos iniciales, dedicados a esta genealogía, se ha preferido abordar una cuestión menos tratada hoy día, como es la de la terminología aplicada al diario en la literatura, ámbito en donde reina la confusión. Si pragmáticamente se acepta la aparición de este nuevo género, debe constatarse a su vez la aparición de un nuevo autor, especialmente conocido por estos textos y que es una suerte de nuevo profesional literario: el diarista moderno. 
peras? ¿La muerte?» $(1965,261)$. De hecho, Dimanche m’attend aparecerá póstumamente.

A partir de los años 1980-90 se desarrolla una práctica de escritura del diario como género literario, concebido y redactado como tal. El texto que marca esta nueva hornada de diarios es Le Mausolée des amants (2001), publicado póstumamente y en el cual Hervé Guibert elabora su diario como la novela de sus amores: la historia de sí es la de un personaje siempre verdadero y sin embargo pensado como un relato en marcha. Unos años antes, Renaud Camus se había hecho célebre con su Journal d'un voyage en France (1981) y luego por su Journal romain (1987), y había suscitado el escándalo con La Campagne de France (1994), diario en el que presentaba opiniones consideradas racistas y antisemitas. A lo largo de sus reflexiones sobre Francia, sus anécdotas de orden sexual, de la evocación detallada de sus dificultades financieras o de sus observaciones sobre el arte a finales del siglo XX, tiene como objetivo «turbar y apasionar» $(2000,259)$ al lector. Marc-Edouard Nabe no tiene otro objetivo - de una forma diferente- con su Journal intime (1993-2000), donde conserva los nombres reales de las personas en un proyecto de «verdad, cueste lo que cueste» $(2000,2971)$. Se podrían citar, en la misma línea, los volúmenes de Carnets (1989-2013) de André Blanchard o los de Main courante (1998-2008) de Jean-Louis Schefer; también los de Mathieu Simonet, que cuenta en Les Carnets blancs (2010) cómo elimina sus libretas ${ }^{13}$. En la misma época, numerosos poetas como Lorand Gaspar, Philippe Jaccottet, Gilles Jouanard, Robert Marteau, Thierry Metz o Lambert Schlechter publican diarios poéticos fechados.

El diario de diarista «profesional» que se impone como forma literaria en Francia a finales del siglo $\mathrm{XX}$, en suma, es una forma narrativa o poética. Tiene como proyecto contar la historia del diarista de cara a un público, con un tono que puede ser crudo o impactante, sin evitar el detalle de las relaciones amorosas o de los sentimientos más ambiguos. «Para el autor de diario, la verdad es un precipicio adorable, donde uno sueña con abandonarse voluptuosamente, sin agarrarse más a nada», escribe Renaud Camus (2000, 308). El diario poético explota una veta próxima que es la de la recogida del mundo y de sí en el mundo, dentro de un momento de escritura. Se trata de construir un ethos: una figura de uno mismo frente al mundo, que uno puede asumir delante del público incluso a riesgo de conmocionarlo y que cambia la mirada que dirige este público sobre los hombres, sobre el mundo y sobre la literatura.

13 Sería muy interesante establecer, en la tradición francesa, una diferencia entre lo que se ha denominado carnet y el diario personal. El primero, entre los que destacan los famosos Carnets de Albert Camus, se compondría más bien de un registro más cercano a la anotación corta, precisa, casi documental. Carecería, en muchos casos, de un desarrollo del Yo como personaje. 


\section{3. El diario literario en España}

En el caso español, hay que esperar directamente a los años 80 y 90 para encontrar los primeros diaristas profesionales concebidos tal y como se ha expuesto en estas páginas.

Sin ser el primero en publicar su diario, Andrés Trapiello es posiblemente el diarista más importante de la historia literaria reciente. Desde 1990 hasta la actualidad, Trapiello ha publicado un total de veinte tomos de su diario, que Jordi Gracia ha calificado como «uno de los proyectos literarios más fascinantes de la literatura contemporánea» (Gracia y Ródenas 2010, 936). En estas páginas, Trapiello narra su vida bajo el título de Salón de pasos perdidos; a lo largo de sus diarios, el Yo narrador, que bien podría ser el Uno narrador, construye su cotidianidad de una forma totalmente literaria y al mismo tiempo autobiográfica. Si bien el autor utiliza el término de novela en marcha para definir a esta saga diarística, y el método de escritura tiende a novelizar el registro cotidiano previo, lo cierto es que tanto la crítica comercial como académica, así como el público lector, interpretan el diario como un texto autobiográfico que, pese a no estar fechado, sigue en su generalidad todas las convenciones del género. Se puede citar a autores como Juan Bonilla (2016) o Félix de Azúa (2013), pero es que incluso el autor se refiere a su texto como diario en numerosas ocasiones (Espada 2016), de tal forma que la reescritura de sus páginas es un simple condicionante pragmático que, sobre todo, incide en la naturaleza editorial del diario. Trapiello escribe, directamente, inserto en un sistema literario al que dirige su obra y en el que se encuentran todos los elementos receptores de la misma: público, crítica cultural y crítica académica. Trapiello es el primer diarista que produce su obra en este contexto, porque además es el primero que cosecha cierta resonancia comercial solamente por su diario; aunque publica antes algunos poemarios, y mantiene una carrera novelística paralela a la publicación de estos diarios, son estos últimos los que en las últimas décadas le han dado fama en el contexto literario español. Esto lo convierte en el claro ejemplo de diarista profesional que se ha sostenido en estas páginas y que concibe su diario como un género puramente literario.

En las últimas décadas, otros autores han ganado fama como diaristas al mismo tiempo que llevaban carreras novelísticas, poéticas o filosóficas. Es el caso de José Jiménez Lozano, que publica en 1985 Los tres cuadernos rojos y que a partir de ahí publica periódicamente un diario de relativo éxito; Miguel Sánchez-Ostiz, que a partir de La casa del rojo (1995) publica su diario con el objetivo de dar fe de su «diario de a bordo de mi vida» (2001, 7); Laura Freixas, que publica en 2013 su diario personal bajo el nombre de Una vida subterránea; o finalmente Salvador Pániker, filósofo cuya entrada en el sistema literario se produce a raíz de la publicación de su diario personal en cuatro famosos tomos a partir de Variaciones 95, aparecido en el año 2002. Si es cierto que estos autores tienen unas carreras novelísticas de éxito, sus textos diarísticos 
cada vez cobran más independencia dentro de sus respectivas obras y facilitan su establecimiento en el sistema literario, de tal manera que su estatus de diaristas es ya una realidad. Son autores, además, que escriben y preparan sus diarios para la publicación, en un contexto en el que el diario ya forma parte de la literatura.

Habría que llegar, sin embargo, a Iñaki Uriarte para encontrar en toda su plenitud a esa figura del diarista profesional a semejanza de Trapiello. Uriarte, que no tenía obra literaria previa, publica a partir de 2010 unos diarios que han tenido un enorme éxito en crítica y público. Aunque él mismo declaraba que «los diarios ni se escriben, ni se publican ni se venden» (Uriarte 2015a, 172), el tiempo se ha encargado de llevarle la contraria, cuando alguien como Muñoz Molina (2015) elogia estos diarios y la crítica en general aplaude cada nueva entrega. En estos diarios no fechados, la entrada es más concisa que en los de Trapiello, y el tono formal es más aforístico, muchas veces cercano al ensayismo de Montaigne. A pesar de ello, a lo largo de sus páginas hay una construcción de un Yo diarístico que resulta finalmente un personaje literario. Además, estos diarios revelan la conciencia editorial del diarista; en la última página publicada, Uriarte señala: «Es absurdo el miedo que le he tomado a escribir. Como si cada línea que yo escribiera fuera a ser leída, escrutada y juzgada por todo el mundo» $(2015$ b , 122). Esto, que podría ser bautizado como la ansiedad del escritor intimista, es lo que define al nuevo diarista del que se viene hablando: su conciencia de estar escribiendo un texto que es privado y al mismo tiempo dirigido al gran público, al sistema literario.

\section{4. Conclusiones}

El nuevo diarista profesional es un escritor literario. En muchas ocasiones su fama es debida al diario y no al resto de su obra -como sí sucedía con Gide, Kafka o Tolstoi- y esto último le otorga al género una solidez en el sistema literario de la que nunca antes había gozado. Se podría hablar, en este sentido, de la aparición de un autor que ya considera al diario la parte más importante de su obra literaria y que es reconocido como escritor gracias a su obra diarística. Ese paso de práctica de escritura subalterna a elemento esencial de la obra literaria total es sumamente importante para entender el establecimiento del diario en el sistema literario.

Una evidencia de este último fenómeno se ha encontrado en las diversas críticas estudiadas, en los contextos francés y español, pero incluso en el canon más rutilante de la crítica literaria actual, El Canon Occidental (1995) de Harold Bloom, puede hallarse rastros de la misma. Bloom incluye aquí, entre los textos más emblemáticos de Dante, Petrarca, Montaigne, Shakespeare o Cervantes, diversos diarios: en la tradición anglosajona destaca los diarios de Ralph Waldo Emerson, en la francesa los de André Gide, en la alemana los de 
Franz Kafka y en la portuguesa cita El libro del desasosiego, el maravilloso diario literario de Fernando Pessoa. En general, el hecho de que Harold Bloom introduzca cuatro textos diarísticos en su canon supone la confirmación de la presencia del diario en el sistema literario internacional. Así, más allá de la selección que haya hecho Bloom, el hecho de destacar los diarios de Kafka y concederles la importancia de sus novelas, como gesto simbólico, es enormemente revelador para el estatus literario de la escritura diarística moderna.

El último paso de este canon -que apenas se detiene en los escritores nacidos después de 1950- sería incluir a los diaristas que se han definido aquí como diaristas profesionales y que sin lugar a dudas llegarán a formar parte del mismo. Dado ese paso, podría confirmarse lo que en este artículo se ha pretendido abordar en los contextos francés y español: la evolución experimentada por el diario para pasar de práctica privada a escritura pública, su paso de diario testimonial a diario personal capaz de ser interpretado desde la literatura, su confirmación como diario literario.

\section{BIBLIOGRAFÍA CITADA}

Aira, César. 2008. «La intimidad». Boletín del Centro de Estudios de Teoría y Crítica Literaria 13-14: 1-8.

Alberca, Manuel. 2017. La máscara o la vida. De la autoficción a la antificción. Málaga: Pálido Fuego.

Audiberti, Jacques. 1965. Dimanche m'attend. París: Gallimard.

Azúa, Félix de. 2013. «La indiscreción de un escritor». Jot Down [en línea]. Acceso 09-052019. https://www.jotdown.es/2013/04/felix-de-azua-la-indiscrecion-de-un-escritor/

Barthes, Roland. 2002a. «Notes sur André Gide et son Journal». En CEuvres complètes I, Roland Barthes, 33-46. París: Seuil.

Barthes, Roland. 2002b. «Alain Girard: Le Journal intime». En Euvres complètes II, Roland Barthes, 806-810. París: Seuil.

Barthes, Roland. 2002c. «Déliberation». En, Euvres complètes V, Roland Barthes, 668-681. París: Seuil.

Barthes, Roland. 2009. Diario de duelo. Barcelona: Paidós.

Basanta, Ángel. 1990. «El gato encerrado». ABC [en línea]. Acceso 25-05-2019. http://hemeroteca.abc.es/nav/Navigate.exe/hemeroteca/madrid/abc/1990/07/21/056.html

Berne-Joffroy. 1944. Présence de Valéry précédé de Propos me concernant par Paul Valéry. París: Plon.

Blanchot, Maurice. 1959. El libro que vendrá. Caracas: Monte Ávila.

Blanchot, Maurice. 1969. L'Entretien infini. París: Gallimard.

Bloom, Harold. 1995. El canon occidental. Barcelona: Anagrama.

Bonilla, Juan. 2016. «Auge de un género: los diarios, literatura del yo». Tam-Tam Press [en línea]. Acceso 09-05-2019. https://tamtampress.es/2016/08/25/auge-de-un-genero-losdiarios-literatura-del-yo-por-juan-bonilla/

Bou, Enric. 1996. «El diario: periferia y literatura». Revista de Occidente 182-183: 121-136.

Bourdieu, Pierre. 2006. Autoanálisis de un sociólogo. Barcelona: Anagrama.

Bourget, Paul. 1920. Essais de psychologie contemporaine II. París: Plon-Nourrit. 
Braud, Michel. 2006. La forme des jours. París: Seuil.

Braud, Michel. 2012. «Lecture et écriture du journal intime au xixe siècle». Interférences littéraires 9: 27-36.

Brunetière, Ferdinand. 1888. «La littérature personnelle». Revue des Deux Mondes: 433-452.

Caballé, Anna. 2015. Pasé la mañana escribiendo. Poéticas del diarismo español. Sevilla: Fundación José Manuel Lara.

Camus, Renaud. 2000. La Campagne de France. Journal 1994. París: Fayard.

Corrado, Danielle. 2000. Le journal intime en Espagne. Aix-en-Provence: Université de Provence.

Del Litto, Victor, ed. 1978. Le journal intime et ses formes littéraires. Genève: Droz.

Didier, Beatrice. 1976. Le journal intime. París: Presses Universitaires de France.

Duhamel, Georges. 1947. Chronique des Pasquier I: Le Notaire du Havre. París: Mercure de France.

Espada, Arcadi. 2016. «Yo vivo peligrosamente». El Mundo [en línea]. Acceso 25-05-2019. https://www.elmundo.es/cultura/2016/01/30/56abb28746163fcc298b4691.html

Freixas, Laura. 1996. «Auge del diario ¿íntimo? En España». Revista de Occidente 182-183: 5-14.

García-Luengo, Eusebio. 1955. «Literatura e intimidad». ABC Sevilla. 11 de noviembre de 1955.

Gascón et alii. 2015. «Diarios». Letras libres 167.

Genette, Gerard. 1999. Figures IV. París: Seuil.

Girard, Alain. 1963. Le Journal intime. París: PUF.

González Ródenas, Soledad. 2005. Juan Ramón Jiménez a través de su biblioteca. Sevilla: Universidad de Sevilla.

Gracia, Jordi y José-Carlos Mainer. 2000. «El diario de escritor». En Historia y crítica de la literatura española, ed. Francisco Rico. Los nuevos nombres: 1975-2000: primer suplemento, coord. Jordi Gracia, vol. 9, tomo 2, 449-459. Barcelona: Crítica.

Gracia, Jordi y Domingo Ródenas de Moya. 2010. Historia de la literatura española: derrota y restitución de la modernidad (1939-2010). Barcelona: Crítica.

Granell, Manuel y Antonio Dorta. 1963. Antología de diarios intimos. Barcelona: Labor.

Jossua, Jean-Pierre. 2004. «Le journal comme forme littéraire et comme itinéraire de vie». Revue des sciences philosophiques et théologiques 87: 703-714.

Krüdener, Madame de. 1975. Écrits intimes et prophétiques de Madame de Krüdener 17851807. París: CNRS.

Lejeune, Philippe. 1975. Le Pacte autobiographique. París: Seuil.

Lejeune, Philippe. 1990. «Un siècle de résistance à l'autobiographie». Tangence 45: 132-146.

Lejeune, Philippe. 1997. «Le journal en procès». En L'autobiographie en procès, ed. Philippe Lejeune, 57-75. París: Université de París X.

Lejeune, Philippe. 2016. Aux origines du journal personnel. París: Honoré Champion.

Luque Amo, Álvaro. 2016. «El diario personal en la literatura: teoría del diario literario». Castilla. Estudios de Literatura 7: 273-306.

Luque Amo, Álvaro. 2018. «La construcción del espacio íntimo en el diario literario». Signa 27: 745-768. https://doi.org/10.5944/signa.vol27.2018.18828

Merry, Bruce. 1979. «The Literary Diary as a Genre». The Maynooth Review 5 (1): 3-19.

Montaigne, Michel de. 2016. Los ensayos. Barcelona: Acantilado.

Muñoz Molina, Antonio. 2015. «Viendo nevar fuera», El País [en línea]. Acceso 26-05-2019. https://elpais.com/cultura/2015/03/23/babelia/1427134505_827622.html

Nabe, Marc-Édouard. 2000. Kamikaze. Journal intime 4. Monaco: Le Rocher. 
Picard, Hans Rudolf. 1981. «El diario como género entre lo íntimo y lo público». 1616 : Anuario de la Sociedad Española de Literatura General y Comparada 4: 115-122.

Pla Barbero, Xavier. 1996. «El autobiografismo ficcional en la obra de Josep Pla». En Mundos de ficción, ed. José María Pozuelo Yvancos y Francisco Vicente Gómez, 12291236. Murcia: Universidad de Murcia.

Proust, Marcel. 2009. En busca del tiempo perdido. El tiempo recobrado. Barcelona: Lumen.

Rivas Carmona, María del Mar. 2008. «La escritura femenina en la lengua inglesa del siglo XVII». Hikma 7: 9-23.

Sagaert, Martine. 2012. «De la difficulté d'editer le Journal de Gide sur un support papier». En Les journaux d'écrivains: enjeux génériques et éditoriaux, ed. Cécile Meynard, 347362. Bern: Peter Lang.

Sánchez-Ostiz, Miguel. 2001. La casa del rojo. Barcelona: Península.

Sawa, Alejandro. 2009. Iluminaciones en la sombra. Madrid: Nórdica.

Schmidt, Siegfried J. 1997. «La auténtica realidad es que la realidad existe: modelo constructivista de la realidad, la ficción y la literatura». En Teorías de la ficción literaria, ed. Antonio Garrido Domínguez, 207-238. Madrid: Arco.

Simón Tarrés, Antonio. 1988. «Memorias y diarios personales de la Cataluña moderna». Historia social 2: 119-134.

Simonet-Tenant, Françoise. 2004. Le journal intime. Genre littéraire et écriture ordinaire. París: Téraèdre.

Torre, Guillermo de. 1970. Doctrina y estética literarias. Madrid: Guadarrama.

Trapiello, Andrés. 1998. El escritor de diarios. Barcelona: Península.

Uriarte, Iñaki. 2015a. Diarios 2004-2007. Logroño: Pepitas de Calabaza.

Uriarte, Iñaki. 2015b. Diarios 2008-2010. Logroño: Pepitas de Calabaza.

Villena, Luis Antonio de. 2015. «Diarios íntimos españoles». El Mundo [en línea]. Acceso 09-05-2019. http://www.elmundo.es/cultura/2015/10/14/561d615ae2704ee36e8b460a.html

Walsch, Francis. 2014. «Lecture, écriture de soi et engagement de l'écrivain. Autour de Sartre lecteur du Journal de Gide durant la drôle de guerre». En Politiques de la littérature. Une traversée du XXe siècle français, ed. L. Côté-Fournier, Élyse Guay y JeanFrançois Hamel, 75-99. Québec: Université du Québec.

Fecha de recepción: 27 de febrero de 2018 .

Fecha de aceptación: 30 de mayo de 2018. 